\title{
HEPATOPROTECTIVE ACTIVITY OF CORDIA OBLIQUA AGAINST PARACETAMOL-INDUCED LIVER TOXICITY ON WISTAR RATS
}

\author{
SIVAKRISHNAN SIVAGNANAM, PRADEEPRAJ DEVARASU
}

\author{
Department of Pharmacy, Annamalai University, Chidambaram, Tamil Nadu, India. Email: sivacdm82@gmail.com
}

Received: 18 April 2019, Revised and Accepted: 15 May 2019

\begin{abstract}
Objective: The ethanolic extract of Cordia obliqua (EECO) Willd. leaves was evaluated for hepatoprotective activity in Wistar rats by inducing hepatic damage with paracetamol.

Methods: The leaves of $C$. obliqua were dried under shade, segregated, pulverized by a mechanical grinder and passed through a 40 mesh sieve. The powdered plant materials were stored in an air-tight container. The above-powdered materials were successively extracted with ethanol by hot continuous percolation method in Soxhlet apparatus for $24 \mathrm{~h}$. The extract was concentrated using a rotary evaporator and subjected to freeze drying in a lyophilizer till dry powder was obtained.

Results: Treatment with EECO at 200 and $400 \mathrm{mg} / \mathrm{kg}$ showed significant decrease in serum glutamate-pyruvate transaminase, serum glutamic oxaloacetic transaminase, alkaline phosphatase, and total bilirubin levels and a significant elevation in the total protein, albumin, and globulin levels in serum when compared with paracetamol treated rats. In histological study of liver, the hepatocytes show moderate cytoplasm and moderately enlarged pleomorphic and hyperchromatic nuclei. The portal triads show mild periportal inflammation composed of lymphocytes, and central veins are normal.
\end{abstract}

Conclusion: On the basis of results, we can conclude that the EECO leaves showed potential hepatoprotective activity in rats.

Keywords: Histopathology, Silymarin, Paracetamol, Cordia obliqua, Hepatoprotective

(C) 2019 The Authors. Published by Innovare Academic Sciences Pvt Ltd. This is an open access article under the CC BY license (http://creativecommons. org/licenses/by/4. 0/) DOI: http://dx.doi.org/10.22159/ajpcr.2019.v12i7.33665

\section{INTRODUCTION}

Liver disease accounts for approximately 2 million deaths per year worldwide, 1 million due to complications of cirrhosis, and 1 million due to viral hepatitis and hepatocellular carcinoma [1,2]. Unfortunately, treatments of choice for liver diseases are controversial because conventional or synthetic drugs for the treatment of these diseases are insufficient and sometimes cause serious side effects [3]. Hundreds of plants have been so far examined to be taken for a wide spectrum of liver diseases $[4,5]$. Natural products, including herbal extracts [6], could significantly contribute to recovery processes of the intoxicated liver. The Cordia obliqua Willd. also called as clammy cherry is a flowering plant species in the genus Cordia belonging to the family Boraginaceae. Conventionally, C. obliqua is used for cooling effects, anthelmintic, expectorant, and diuretic. It lessens thirst and scalding of urine, removes pains in the joints, and it is used as treatment of diseases of spleen and leprosy. Stem bark [7] is used as a mild tonic, kernels are a remedy in treatment in ringworm, and leaves are used to treat ulcers and headache externally. Seeds are used as anti-inflammatory [8] and antimicrobial agent [9].The Javanese use the bark in the treatment of fevers [10]. Our literature survey revealed that the hepatoprotective activity of ethanolic extract of $C$. obliqua was not investigated, Hence these activities have been investigated in the present study.

\section{METHODS}

\section{Collection and identification of Cordia obliqua}

C. obliqua $[11,12]$ was collected from B. Maduvankarai, Chidambaram Taluk, Cuddalore, Tamil Nadu, India. Taxonomic identification was made from Botanical Survey of Medicinal Plants Unit Siddha, Government of India, Palayamkottai.

\section{Extraction and isolation of Cordia obliqua}

C. obliqua leaves were collected and extract prepared from ethanol by hot continuous percolation method in Soxhlet apparatus for $24 \mathrm{~h}$. The leaves were dried under shade, segregated, pulverized by a mechanical grinder, and passed through a 40 mesh sieve. The powdered plant materials were stored in an air-tight container. The above-powdered materials were successively extracted with ethanol by hot continuous percolation method in Soxhlet apparatus for $24 \mathrm{~h}$. The extract was concentrated using a rotary evaporator [13] and subjected to freeze drying in a lyophilizer [14] till dry powder was obtained.

\section{Chemicals}

All the drugs, chemicals, and reagents used for biochemical estimation were purchased from Sigma Aldrich, Mumbai.

\section{Animals}

Wistar rats weighing 150-200 g housed in standard environmental conditions were used. The protocol was approved by the Institutional Animal Ethics Committee, Annamalai University (approved number: AU-IAEC/1233/1/19). They were fed with standard rodent diet and water ad libitum.

\section{Hepatoprotective activity}

\section{Experimental design}

Rats were divided randomly into five groups of six animals each and treated for 1 week (7 days) as follows:

- Group-I: Animals served as normal control, treated with vehicle ( $0.5 \%$ carboxymethyl cellulose) $1 \mathrm{ml} / \mathrm{kg}$ once daily for 7 days orally

- Group-II: Animals served as toxic control will receive $1 \mathrm{ml}$ vehicle for 7 days, and on the $5^{\text {th }}$ day paracetamol $2 \mathrm{~g} / \mathrm{kg}$, body weight will be given per orally

- Group III: Animals received ethanolic extract of $C$. obliqua (EECO) Willd. $200 \mathrm{mg} / \mathrm{kg}$ body weight, orally daily for 7 days. A single dose of paracetamol $2 \mathrm{~g} / \mathrm{kg}$ body weight will be administered per orally on the $5^{\text {th }}$ day

- Group-IV: Received EECO Willd. $400 \mathrm{mg} / \mathrm{kg}$ body weight, by orally 
daily for 7 days. A single dose of paracetamol $2 \mathrm{~g} / \mathrm{kg}$ body weight will be administered per orally on the $5^{\text {th }}$ day

- Group-V: Received silymarin $25 \mathrm{mg} / \mathrm{kg}$ body weight by orally daily for 7 days and a single dose of paracetamol $2 \mathrm{~g} / \mathrm{kg}$ body weight will be administered per orally on the $5^{\text {th }}$ day.

Biochemical analysis

Dissection and homogenization

On the $8^{\text {th }}$ day, all animals were sacrificed by cervical dislocation. Blood sample was collected in previously labeled centrifuging tubes and allowed to clot for $45 \mathrm{~min}$ at room temperature [15]. Serum was separated by centrifugation at $2500 \mathrm{rpm}$ for $15 \mathrm{~min}$.

\section{Biochemical estimation}

Serum was separated and used for the estimation of biochemical parameters, namely serum glutamic oxaloacetic transaminase (SGOT), serum glutamate-pyruvate transaminase (SGPT), albumin [16], total bilirubin (TB) [17], alkaline phosphate [18,19], globulin, and total protein (TP) in autoanalyzer (Shimadzu, Japan).

\section{Histopathological observation}

The liver was excised from the animals and washed with the normal saline. The materials were fixed in $10 \%$ buffered neutral formalin, then washed, dehydrated in descending grades of isopropanol, and finally, rinsed with xylene. The tissues were then embedded in molten paraffin wax. Sections of $5 \mathrm{~m}$ thickness were taken using a microtome, processed in alcohol-xylene series and were stained with hematoxylin and eosin [20] and subjected to histopathological examination.

\section{Statistical analysis}

The values were expressed as mean \pm standard error of mean $(n=6)$. Statistical analysis were performed with one-way analysis of variance followed by Student's t-test using GraphPad InStat Software and were used to determine the statistical significance. ${ }^{*} \mathrm{p}<0.01,{ }^{* *} \mathrm{p}<0.05$, and ${ }^{* * *} \mathrm{p}<0.001$, when compared with control and toxicant group as applicable.

\section{RESULTS}

Treatment with EECO at 200 and $400 \mathrm{mg} / \mathrm{kg}$ showed significant decrease in SGPT, SGOT, alkaline phosphatase (ALP), and TB levels are shown in Table 1, and a significant elevation in the TP, albumin, and globulin levels are shown in Table 2 when compared with paracetamoltreated rats. Standard drug silymarin also exhibited similar results significantly.

\section{HISTOPATHOLOGICAL RESULTS}

The hepatoprotective effect of EECO was confirmed by histopathological examination of the liver tissue of control and treated animals: Fig. 1: Liver section of normal control rats (Group I) shows normal architecture. The central veins, sinusoids, and portal triads appear normal. The hepatocytes show moderate cytoplasm and round-to-oval nuclei. There is no periportal inflammation. Fig. 2: Toxic control (paracetamol $2 \mathrm{~g} / \mathrm{kg}$ )-treated rats (Group II) show the architecture are partly effaced. The central veins, sinusoids, and portal triads appear congested. The hepatocytes show feathery degeneration and show moderate cytoplasm and round-to-oval nuclei. There is periportal inflammation. Fig. 3: Standard drug (silymarin $25 \mathrm{mg} / \mathrm{kg}$ )-treated rats (Group III) indicate that the hepatocytes have shown normal size with normal portal area. There is mild increase in fibrous connective tissues with minimal sign of hepatotoxicity. Regenerative activity is maximum. Fig. 4: EECO (200 mg/kg)-treated rats (Group IV) show liver with mild sign of hepatotoxicity, tissue with typical lobular arrangement, and minimal

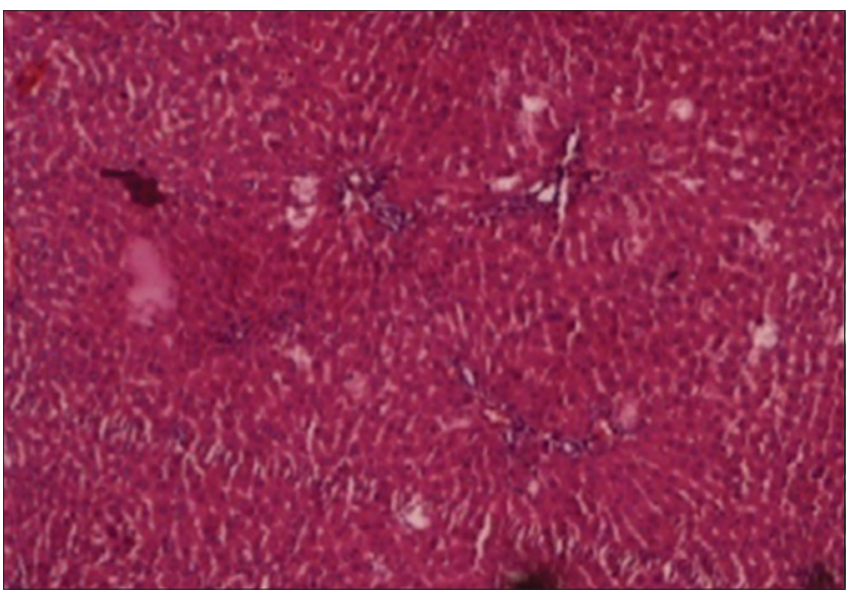

Fig. 1: Control rat liver

Table 1: Effect of ethanolic extract of leaves of Cordia obliqua on serum enzymes (serum glutamate-pyruvate transaminase, serum glutamic oxaloacetic transaminase, and total bilirubin) in paracetamol-treated rats

\begin{tabular}{lllll}
\hline S.No. & Groups & SGOT (IU/L) & SGPT (IU/L) & TB (mg/dl) \\
\hline 1 & Group I (control) & $75.66 \pm 2.065$ & $58.5 \pm 2.34$ & $0.76 \pm 0.05$ \\
2 & Group II (negative control) & $97.66 \pm 2.87^{*}$ & $87.16 \pm 3.65^{* *}$ & $1.03 \pm 0.05^{* * *}$ \\
3 & Group III (standard) & $51.66 \pm 3.44^{*}$ & $49 \pm 3.74^{* *}$ & $0.76 \pm 0.08^{*}$ \\
4 & Group IV (Test - I) & $76.16 \pm 4.70^{* *}$ & $82 \pm 1.788^{* *}$ & $0.83 \pm 0.08^{*}$ \\
5 & Group V (Test - II) & $67.83 \pm 6.04^{* *}$ & $58.33 \pm 3.77^{* *}$ & $0.71 \pm 0.12^{*}$ \\
\hline
\end{tabular}

Data are expressed as mean \pm SEM, $n=6$ rats per group. P values, ${ }^{*} \mathrm{p}<0.01,{ }^{* *} \mathrm{p}<0.05,{ }^{* * *} \mathrm{p}<0.001$ compared to negative control. One way ANOVA followed by student's $\mathrm{t}$-test. $\mathrm{a} \rightarrow$ Group II compared to Group I; $\mathrm{b} \rightarrow$ Group II compared to Group III, IV and V. SGPT: Serum glutamate-pyruvate transaminase, SGOT: Serum glutamic oxaloacetic transaminase, TB: Total bilirubin, ANOVA: Analysis of variance, SEM: Standard error of mean

Table 2: Effect of ethanolic extract of leaves of Cordia obliqua on serum enzymes (albumin, alkaline phosphatase, globulin, and total protein) in paracetamol-treated rats

\begin{tabular}{lllll}
\hline S.No. & Groups & Albumin (g/dl) & ALP (IU/L) & Globulin (g/dl) \\
\hline 1 & Group I (control) & $2.63 \pm 0.33$ & $115.16 \pm 4.30$ & $3.033 \pm 0.21$ \\
2 & Group II (negative control) & $1.75 \pm 0.18^{*}$ & $279.66 \pm 6.53^{* *}$ & $1.88 \pm 0.17^{*}$ \\
3 & Group III (standard) & $2.08 \pm 0.22^{*}$ & $167.5 \pm 8.21^{* *}$ & $2.28 \pm 0.24^{*}$ \\
4 & Group IV (Test - I) & $2.36 \pm 0.216^{*}$ & $230.5 \pm 6.12^{* *}$ & $2.66 \pm 0.19^{*}$ \\
5 & Group V (Test - II) & $2.13 \pm 0.23^{*}$ & $198 \pm 8.24^{* *}$ & $6.44 \pm 0.31^{*}$ \\
\hline
\end{tabular}

Data are expressed as mean \pm SEM, $n=6$ rats per group. P values, ${ }^{*} \mathrm{p}<0.01,{ }^{* *} \mathrm{p}<0.05,{ }^{* * *} \mathrm{p}<0.001$ compared to negative control. One way ANOVA followed by student's t-test. $a \rightarrow$ Group II compared to Group I; $b \rightarrow$ Group II compared to Group III, IV and V. TP: Total protein, ALP: Alkaline phosphatase, ANOVA: Analysis of variance, SEM: Standard error of mean 


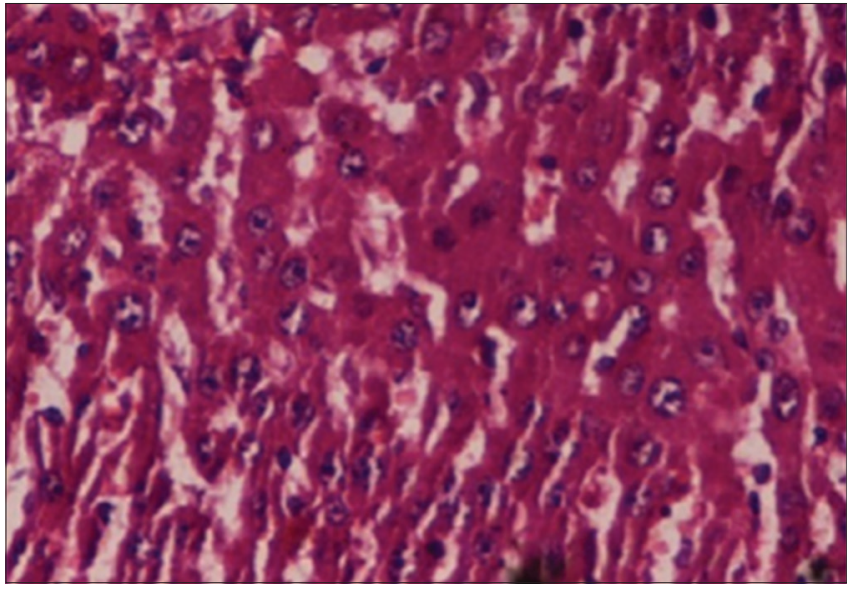

Fig. 2: Paracetamol (2 g/kg)-treated rat liver

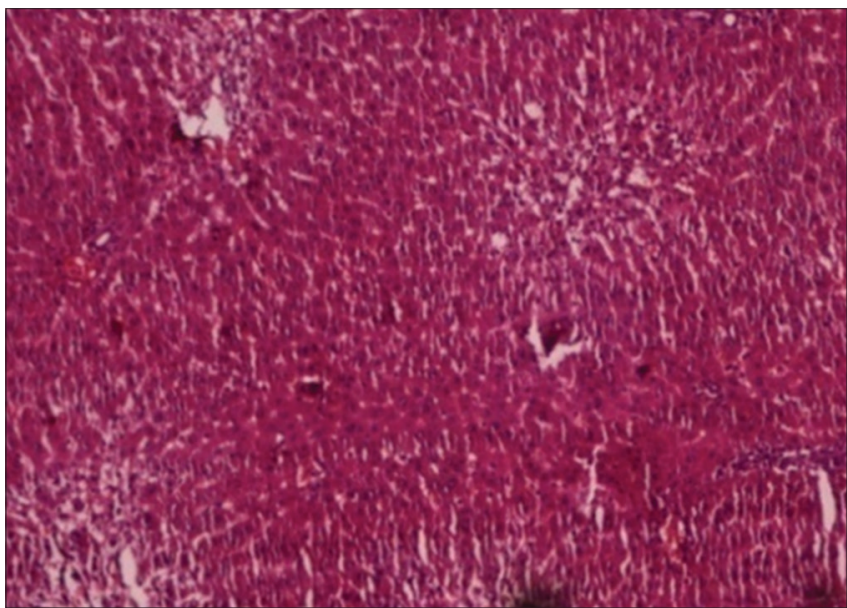

Fig. 3: Standard (silymarin $25 \mathrm{mg} / \mathrm{kg})+$ paracetamol $(2 \mathrm{~g} / \mathrm{kg})$ rat liver

centrilobular necrosis. The portal triads show mild periportal inflammation composed of lymphocytes. Fig. 5: EECO (400 mg/ $\mathrm{kg}$ )-treated rats (Group V) hepatocytes show moderate cytoplasm and moderately enlarged pleomorphic and hyperchromatic nuclei. The portal triads show mild periportal inflammation composed of lymphocytes and central veins are normal.

\section{CONCLUSION}

In the present study, intoxication of Wistar rats with paracetamol when compared with control rats. Treatment with EECO at 200 and $400 \mathrm{mg} / \mathrm{kg}$ showed significant decrease in SGPT, SGOT, ALP, and TB levels and a significant elevation in the TP, albumin, and globulin levels in serum when compared with paracetamol-treated rats. Standard drug silymarin also exhibited similar results significantly. In histopathological study, the paracetamol-induced rats showed that the architecture is partly effaced. The central veins, sinusoids, and portal triads appear congested. The hepatocytes show feathery degeneration and show moderate cytoplasm and round-to-oval nuclei. There is periportal inflammation. Maximum dose $(400 \mathrm{mg} / \mathrm{kg})$ of EECO treated rats shows normal hepatocytes. The hepatocytes shows moderate cytoplasm, moderately enlarged pleomorphic and hyperchromatic nuclei. The portal triads show mild periportal inflammation composed of lymphocytes, and central veins are normal. Standard drug (silymarin $25 \mathrm{mg} / \mathrm{kg}$ )-treated rats indicate that the hepatocytes have shown normal size with normal portal area. There is mild increase in fibrous connective tissues with minimal sign of hepatotoxicity. Regenerative activity is maximum.

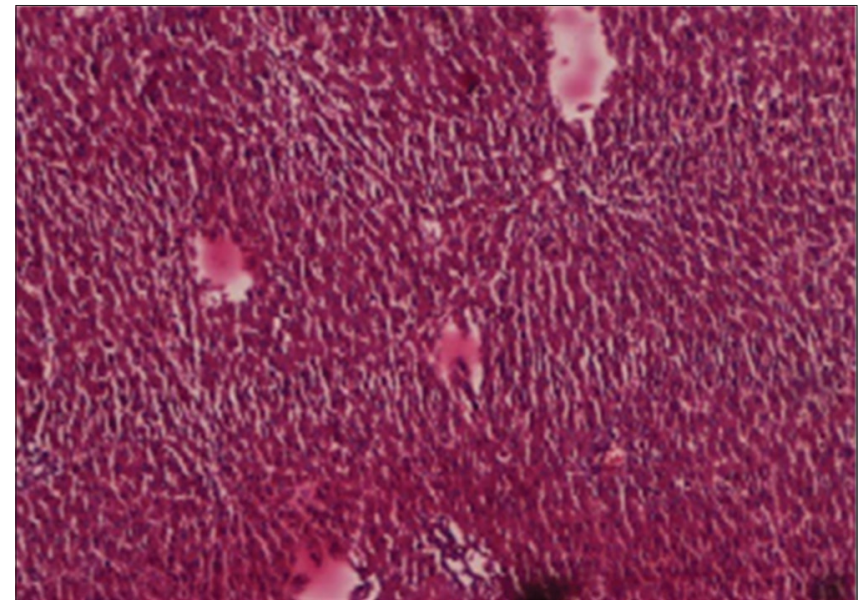

Fig. 4: Paracetamol (2 g/kg) +treated group $200 \mathrm{mg} / \mathrm{kg}$ of Cordia obliqua

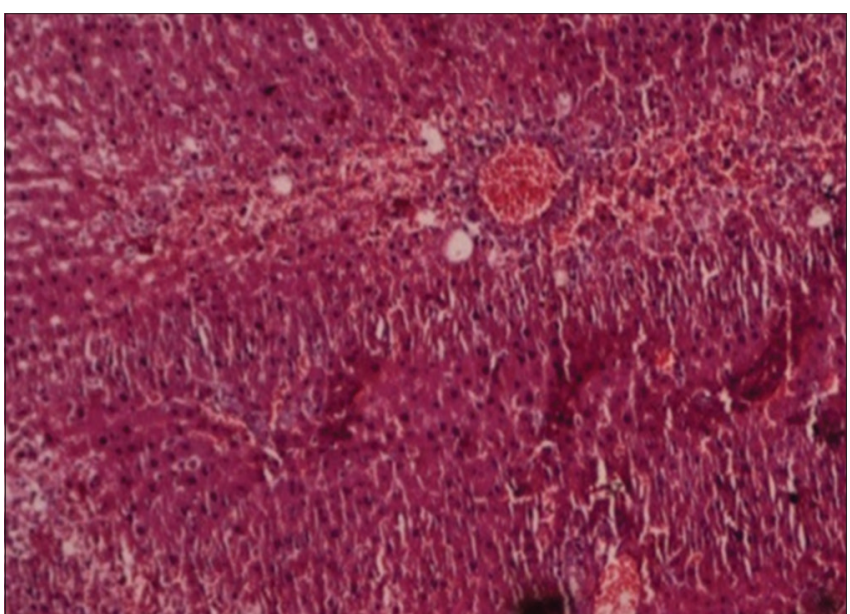

Fig. 5: Paracetamol (2 g/kg) +treated group $400 \mathrm{mg} / \mathrm{kg}$ of Cordia obliqua

On the basis of results, we can conclude that the EECO leaves showed potential hepatoprotective activity in rats. Further studies are in progress to isolate the active constituents of $C$. obliqua and also to evaluate the exact mechanism of action for the hepatoprotective activity.

\section{AUTHORS' CONTRIBUTION}

All the authors contributed equally to the paper.

\section{COMPETING INTEREST}

The authors declare no conflict of interest.

\section{REFERENCES}

1. Mokdad AA, LopezAD, Shahraz S, Lozano R, Mokdad AH, Stanaway J, et al. Liver cirrhosis mortality in 187 countries between 1980 and 2010: A systematic analysis. BMC Med 2014;12:145.

2. Asrani SK, Devarbhavi H, Eaton J, Kamath PS. Burden of liver diseases in the world. J Hepatol 2019;70 Suppl 1:151-71.

3. Kumar $\mathrm{CH}$, Ramesh A, Kumar JS, Ishaq BM. A review on hepatoprotective activity of medicinal plants. Int J Pharm Sci Res 2011;2 Suppl 3:501-15.

4. Asadi-Samani M, Rafieian-Kopaei M, Azimi N. Gundelia: A systematic review of medicinal and molecular perspective. Pak J Biol Sci 2013;16 Suppl 21:1238-47.

5. Asadi-Samani M, Bahmani M, Rafieian-Kopaei M. The chemical composition, botanical characteristic and biological activities of Borago officinalis: A review. Asian Pac J Trop Med 2014;7S1:S22-8. 
6. Asadi-Samani M, Kafash-Farkhad N, Azimi N, Fasihi A, Alinia-Ahandani E, Rafieian-Kopaei M. Medicinal plants with hepatoprotective activity in Iranian folk medicine. Asian Pac J Trop Biomed 2015;5 Suppl 2:146-57.

7. Tiwari K, Srivastava SD. Chemical investigation of the stem bark of Cordia obliqua. Planta Med 1979;36 Suppl 2:191-2.

8. Prakash NU, Bhuvaneswari S, Balamurugan A, Radhika B. Studies on phytochemistry of 100 plants in Chennai, India. Br J Pharm Res 2013;3 Suppl 3:407-19.

9. Yadav R, Yadav S. Evaluation of antimicrobial activity of seeds and leaves of Cordia obliqua Willd against some oral pathogens. Indo Am J Pharm Res 2013;3:6035-43.

10. Thirupathi K, Kumar SS, Raju V, Ravikumar B, Krishna D, Mohan GK. A review of medicinal plants of the genus Cordia: Their chemistry and pharmacological uses. J Nat Remedies 2008;8 Suppl 1:1-10.

11. Parmar C, Kaushal MK. Wild Fruits of the Sub-Himalayan Region. Wild fruits of the Sub-Himalayan Region. New Delhi: Kalyani Publication; 1982. p. 136.

12. Gupta R, Gupta GD. A review on plant Cordia obliqua Willd.(Clammy cherry). Pharmacogn Rev 2015;9 Suppl 18:127-31.

13. Azmir J, Zaidul I, Rahman M, Sharif KM, Mohamed A, Sahena F, et al. Techniques for extraction of bioactive compounds from plant materials: A review. J Food Eng 2013;117 Suppl 4:426-36.
14. Sivakrishnan S, Kavitha J, Muthu AK. Antioxidant potential, total phenolic and flavonoids content of aerial parts of ethanolic extract of Albizia procera (Family: Mimosoideae). Asian J Pharm Clin Res 2013;6 Suppl 1:108-10.

15. Sivakrishnan S, Kottaimuthu A. Hepatoprotective activity of ethanolic extract of aerial parts of Albizia Procera Roxb (Benth.) against paracetamol induced liver toxicity on wistar rats. Int J Pharm Pharm Sci 2014;6 Suppl 1:233-8.

16. Dhivya JV, Santhy KS. Demystifying the ethnomedicinal plant Morinda pubescens with ethnopharmacological, phytochemical and pharmacotoxicological evidence. J Crit Rev 2018;5 Suppl 5:1-6.

17. Vijayanirmala R, Abinaya R, Velpandian V. Toxicological screening of a novel siddha polyherbal formulation "Siringipaerathi Chooranam". Int J Curr Pharm Res 2019;11 Suppl 2:18-24.

18. Sumalatha S, Padma D, Pai KS, Kotian SR, Kumar N, Bhat K. Hepatoprotective activity of aqueous extract of Caesalpinia bonduc against CCL4 induced chronic hepatotoxicity. Int J Pharm Pharm Sci 2016;8 Suppl 4:207-11.

19. Vasantharaja D, Ramalingam V. Neurotoxic effect of titanium dioxide nanoparticles: Biochemical and pathological approach in male wistar rats. Int J Appl Pharm 2018;10 Suppl 4:74-81.

20. Galigher AE, Kozloff EN. Essentials of Practical Microtechnique. Philadelphia, PA: Lea and Febiger; 1971. 